\title{
Expression profiling of cardiovascular disease
}

\author{
Stephen Archacki and Qing Wang* \\ Center for Molecular Genetics, Department of Molecular Cardiology, Lerner Research Institute; Center for Cardiovascular Genetics, \\ Department of Cardiovascular Medicine, The Cleveland Clinic Foundation, Cleveland, OH, USA; and Department of Biological, \\ Geological and Environmental Sciences Cleveland State University, Cleveland, OH 44115, USA \\ *Correspondence to: Tel: +1 216445 0570; Fax: +1 216444 2682; E-mail: wangq2@ccf.org
}

Date received (in revised form): 30th April 2004

\begin{abstract}
Cardiovascular disease is the most important cause of morbidity and mortality in developed countries, causing twice as many deaths as cancer in the USA. The major cardiovascular diseases, including coronary artery disease (CAD), myocardial infarction (MI), congestive heart failure (CHF) and common congenital heart disease (CHD), are caused by multiple genetic and environmental factors, as well as the interactions between them. The underlying molecular pathogenic mechanisms for these disorders are still largely unknown, but gene expression may play a central role in the development and progression of cardiovascular disease. Microarrays are high-throughput genomic tools that allow the comparison of global expression changes in thousands of genes between normal and diseased cells/tissues. Microarrays have recently been applied to CAD/MI, CHF and CHD to profile changes in gene expression patterns in diseased and non-diseased patients. This same technology has also been used to characterise endothelial cells, vascular smooth muscle cells and inflammatory cells, with or without various treatments that mimic disease processes involved in CAD/MI. These studies have led to the identification of unique subsets of genes associated with specific diseases and disease processes. Ongoing microarray studies in the field will provide insights into the molecular mechanism of cardiovascular disease and may generate new diagnostic and therapeutic markers.
\end{abstract}

Keywords: microarray analysis, expression profiling, coronary artery disease, heart failure, congenital heart disease, endothelial cells, smooth muscle cells, inflammation

\section{Introduction}

Gene expression is thought to be central to the pathogenesis or progression of coronary artery disease (CAD)/atherosclerosis, congestive heart failure (CHF) and common congenital heart disease (CHD). Microarray analysis is a powerful technique for high-throughput, global transcriptonomic profiling of gene expression. It holds great promise for analysing the genomic basis of various complex diseases and permits the analysis of thousands of genes simultaneously, both in diseased and nondiseased tissues and/or cell lines.

Microarrays are made by depositing spots of DNA on a solid support such as a coated glass surface. ${ }^{1}$ A flat glass surface makes it possible (i) to array molecules in a parallel fashion, (ii) to miniaturise the procedure and (iii) to use fluorescent dyes for detection and thus avoid radioactivity. This differs in several ways from conventional methods such as filter-based supports of charged nylon and nitrocellulose for studying mRNA expression.

A variety of technologies has been used to produce microarrays. Spotted cDNA arrays, produced by deposition of polymerase chain reaction (PCR) products, and GeneChip oligonucleotide arrays (Affymetrix; Santa Clara, CA), produced by in situ synthesis of oligonucleotides, have both been used successfully. Microarrays can now be tailored to focus on a specific set of genes (eg the Cardiochip, with genes related to the cardiovascular system only). The advantages of cDNA arrays are that they are focused to a specific pathway or functional class of genes and will identify the gene(s) of particular interest in the tissue studied. Use of this smaller chip is less expensive, and the same sample can be used to compare similar genes in several species. The limitation of cDNA arrays, however, is that only a very limited set of genes can be evaluated. Oligonucleotide arrays have the advantage of allowing one to monitor every gene in a genome at the same time, rather than focussing on a particular subset of genes. The disadvantage is that this method is expensive and the arrays must be made commercially. At this time, only a few organisms (human, mouse and rat) are available for studies.

Microarrays can serve to complement other genetic and genomic tools, including positional cloning ${ }^{2}$ and proteomics, ${ }^{3}$ to understand the underlying biological pathways that trigger 
or facilitate the development of CAD/atherosclerosis, $\mathrm{CHF}$ or common CHD. In this paper, the authors review the current status of microarray studies in profiling gene expression in cardiovascular disease, with a particular focus on human tissues and cells.

\section{Expression profiling of CAD}

CAD is caused by an accumulation of atherosclerotic plaques (atherosclerosis) in the walls of the coronary arteries. Atherosclerosis leads to symptoms of stable angina if no clinically apparent plaque rupture or significant breach of the arterial wall occurs, but it will result in unstable angina, acute myocardial infarction (MI) or sudden cardiac death once the arterial wall integrity is lost and thrombosis has occurred.

In the USA and most other Western countries, CAD is the leading cause of morbidity and mortality. In the USA alone, it caused almost one million deaths in 1999 - twice the number caused by cancer and ten times the number caused by accidents. ${ }^{4}$ Despite significant medical advances, MI due to CAD (and strokes) is responsible for more deaths than all other causes combined.

There are two main theories that explain the development of atherosclerosis. First, high levels of cholesterol in the blood injure the endothelial cells of a coronary artery, causing an inflammatory reaction and enabling cholesterol and other fatty materials to accumulate there. Secondly, repeated injury to the wall of the artery may occur through various mechanisms involving the immune system or by direct toxicity with substances such as nicotine or homocysteine, leading to the recruitment and accumulation of inflammatory cells. ${ }^{5}$ In both cases, there are changes that can lead to the formation of atheromas and plaques. These two theories probably overlap and are not mutually exclusive. To date, several microarray studies have been reported to profile gene expression in CAD using human tissues; one study from the authors' group focused on the identification of genes differentially expressed in $\mathrm{CAD}$ and non-CAD coronary arteries, ${ }^{6}$ and the other studies have characterised gene expression in atherosclerotic plaques and plaque rupture. ${ }^{7-10}$

Four microarray studies have so far been reported for the characterisation of atherosclerosis, one of which focused on restenosis after coronary interventions. ${ }^{9}$ The current authors used oligonucleotide arrays to study $>12,000$ genes for their expression in human coronary arteries, the target organ of CAD (Table 1). ${ }^{6}$ Fifty-six genes showed differential expression. In the atherosclerotic coronary artery tissues, the expression of 55 genes was increased, whereas only one gene - encoding glutathione-S-transferase (GST), a reducing agent - showed downregulated expression. This study detected the expression of genes previously linked to the generation of CAD, such as osteopontin expressed in smooth muscle cells, vascular cell adhesion molecule (VCAM)-1 expressed in endothelial cells and matrix metalloprotease $(M M P)-9$ expressed in macrophages. This lends credibility to expression profiling as a valid approach for studying gene expression in CAD.

The associations of 49 genes appeared to be novel and had not previously been shown to be associated with CAD. These included genes encoding retinoic acid responder binding (RAR) protein, butyrophilin, steroidogenic acute regulatory protein (STAR), provirus integration site for Moloney murine leukemia virus-2 (PIM-2), signal transducer and activator of transcription-91 (STAT-91) and cathepsins $\mathrm{K}$ and $\mathrm{H}$. The $R A R$ gene is regulated by vitamin A signalling pathways and upregulates the expression of the scavenger receptor CD $36 ;{ }^{11}$ butyrophilin has receptor functions that mediate the transfer of lipid; ${ }^{12}$ and cathepsins $\mathrm{K}$ and $\mathrm{H}$ are lysosomal proteases involved in protein degradation. ${ }^{13,14}$ STAR is the rate-limiting step in steroidogenesis for the transfer of cholesterol into the mitochondria. ${ }^{15}$ The PIM-2 gene is present in mitogenically stimulated hematopoietic cells ${ }^{16}$ and is expressed widely in the media of coronary arteries. ${ }^{6}$ The STAT-91 gene is a signal transducer and activator of transcription in haematopoietic

Table I. Expression profiling of coronary arteries.

\begin{tabular}{|c|c|c|}
\hline Target tissue & Experimental treatment & Number of genes affected \\
\hline Intact coronary arteries ${ }^{6}$ & $\begin{array}{l}\text { Severe atherosclerosis versus } \\
\text { non-atherosclerotic arteries }\end{array}$ & 56 \\
\hline Diffuse survey of several arteries ${ }^{7}$ & $\begin{array}{l}\text { Documentation of gene expression } \\
\text { in atherosclerotic tissue }\end{array}$ & 75 \\
\hline $\begin{array}{l}\text { Coronary plaques from patients } \\
\text { with stable or unstable angina }{ }^{8}\end{array}$ & Ruptured plaque material & 5 \\
\hline $\begin{array}{l}\text { Atherosclerotic plaque from human } \\
\text { coronary arteries } 9\end{array}$ & Specimens retrieved by novel helix cutter & 201 \\
\hline Human atherosclerotic plaque ${ }^{10}$ & Specimens from ruptured plaque & $\begin{array}{l}\text { Focus on perilipin; } \\
\text { consistently upregulated }\end{array}$ \\
\hline
\end{tabular}


cells. ${ }^{17}$ Intercellular adhesion molecule 2 (ICAM-2) is another novel gene whose expression is increased in CAD tissues, and it is expressed mainly in endothelial cells. ${ }^{6}$ GST is the only gene whose expression is reduced in CAD tissues, and it encodes a reducing enzyme. ${ }^{18}$ The most significant group of genes identified in the present authors' study were involved in inflammatory processes and consisted of genes expressed by $\mathrm{B}$ and T lymphocytes, as well as macrophages. Other genes included five genes involved in lipid transfer, oxidation and metabolism; nine genes involved in cell migration, adhesion and matrix degradation; 12 genes involved in cell necrosis, apoptosis and proliferation; and several genes with currently unknown functions.

A cDNA microarray study was used to analyse 18,376 genes for changes in expression in whole-mount human atherosclerotic plaques from the internal and external iliac arteries, aorta, popliteal artery, posterior tibial artery and the tibiofibular trunk with advanced lesions as compared with normal arteries. ${ }^{7}$ Similar to the earlier study by Archacki et al., ${ }^{6} 17$ genes previously connected to atherosclerosis, eg those coding for actin, cathepsin S, apoE and P-glycoprotein, were identified, which validates microarray analysis as a valid approach for studying gene expression in atherosclerosis. ${ }^{7}$ The study identified 75 new differentially expressed genes, 44 of which were upregulated in advanced lesions. Differential expression of Janus kinase 1(JAK-1), vascular endothelial growth factor (VEGF) receptor-2 and continuous domain-31 (CD31) in atherosclerotic plaques was confirmed with reverse-transcription PCR and immunocytochemistry. JAK-1 is a protein kinase which may activate platelet-derived growth factor- $\beta$ (PDGF) signalling. ${ }^{7}$ VEGF receptor-2 is a receptor for angiogenic factor VEGF, it acts as an early marker of vasculature in embryogenesis. ${ }^{7}$ CD31 is also an endothelial cell marker that is involved in monocyte and T-cell adhesion to endothelial cells. ${ }^{7}$ These studies support the current authors' hypothesis that endothelial dysfunction is an early triggering event for the development of CAD. ${ }^{2}$ Thirty-one genes were downregulated in advanced lesions, whereas the Archacki study ${ }^{6}$ identified only one downregulated gene in diseased coronary artery tissues. A limitation of the Hiltunen et al. study is that various arteries were utilised, thus the interpretation of the data may be challenging as different arteries may have unique characteristics. ${ }^{7}$ The Hiltunen et al. study did not share any genes in common with those found in the current authors' study, discussed above; this discrepancy in gene identification between studies appears to be a common finding in microarray analysis of atherosclerosis. The potential explanations for this incongruity may be that different arteries (coronary artery versus other atherosclerotic tissues) were used in different studies, and that the arteries used were at different stages of disease.

The third of the aforementioned microarray analyses was a small-scale study with cDNA arrays, in which cDNA probes were hybridised to nylon arrays containing only 482 genes involved in haemostasis, inflammation and cell adhesion. ${ }^{8}$ The study investigated gene expression in human coronary plaques from patients with stable or unstable angina. One gene, encoding tissue factor, showed increased expression in unstable angina samples, whereas five genes - including anticoagulant protein $S$, cyclooxygenase-1 (COX-1), interleukin (IL)-7 and the chemokines monocyte chemotactic protein $(M C P)-1$ and -2 - were expressed at lower levels in unstable angina samples.

In the fourth microarray study, rather than investigating coronary artery disease per se, the authors focused on restenosis, the most important limitation of percutaneous angioplasty procedures (a common surgical treatment for patients with coronary artery disease). ${ }^{9}$ Zohlnhofer et al. retrieved tissue specimens from 16 patients with symptomatic in-stent restenosis using a novel helix cutter. The control samples included media specimens from seven gastrointestinal arteries and seven coronary arteries from cardiac transplantation. Atlas cDNA arrays (human cancer 1.2, human 1.2 cardiovascular, and stress arrays, Clontech) were used, and a total of 2,435 genes were examined. The study identified several genes that had previously been reported to be expressed in smooth muscle cells and regulated in neointima and restenosis. These included upregulation of the thrombospondin-1 (TSP-1), 70-kDa heat shock protein $B, C O X-1$ genes and downregulation of desmin. The study also identified two new genes that are connected to restenosis, FK506 binding protein-12 (FKBP-12) (upregulated) and the gene encoding the mammary-derived growth inhibitor (MDGI) (downregulated). MDGI is a potent tumour suppressor, ${ }^{19,20}$ and downregulation of MDGI may lead to proliferation and migration of smooth muscle cells, resulting in restenosis after coronary interventions. ${ }^{21}$ Upregulation of FKBP-12 is significant because it is involved in controlling transforming growth factor- $\beta$ (TGF- $\beta$ ) signalling and may prevent cycle arrest, leading to the re-occlusion of coronary arteries by the proliferation of smooth muscle cells. ${ }^{19}$ This latter study lent support to the testing of Rapamycin (sirolimus) as a novel pharmacological approach to preventing restenosis, as it binds to FKBP-12 and downregulates TGF- $\beta$ inhibitory activity. ${ }^{22}$ The potential use of Rapamycin to prevent restenosis is also supported by the report that it inhibits smooth muscle cell (SMC) migration and proliferation and intimal thickening after balloon angioplasty in a porcine model of restenosis. $^{23}$

In addition to microarray analysis, suppression subtractive hybridisation ( $\mathrm{SSH}$ ) technology was successfully used to study gene expression patterns in whole-mount human stable and ruptured plaques. ${ }^{10,24}$ The details of the procedures involved in SSH have been described by Faber et al. ${ }^{10,24}$ Compared with microarray analysis, SSH is more time-consuming but can lead to the identification of low-abundant sequences which may be missed by microarray technology. Perilipin is a phosphoprotein present on the surface of intracellular lipid droplets in adipocytes and steroidogenic cells, ${ }^{25,26}$ Faber et al. 
reported that it had a twofold difference in expression and was upregulated in ruptured plaques. As a result of this finding, it was hypothesised that the overexpression of perilipin increases triacylglycerol storage by reducing triacylglycerol hydrolysis. ${ }^{27,28}$ Consequently, this increase in lipid retention may lead to plaque destabilisation and rupture. Perilipin was found to be consistently expressed in eight ruptured plaques and was completely absent in stable plaques, identifying it as a unique marker. In addition, fibronectin and immunoglobulin $\lambda$ chain were downregulated in ruptured plaques.

In summary, the studies discussed above highlight the importance of using microarrays to identify genes with potential roles in the generation of atherosclerosis, including the evolution of plaque and plaque rupture. Novel genes have been identified which may serve as focal points of future functional and pharmacological studies in an effort to alter the process of atherosclerosis. Furthermore, the combination of microarray analysis and positional cloning may provide a powerful synergy in the characterisation of the molecular bases of human diseases. First, the genes identified by microarray analysis become the strong candidate genes if they are located in a previously mapped genetic susceptibility locus for the disease. Secondly, the results from microarray analyses may provide independent supportive evidence for the new signalling pathway for the pathogenesis of the disease identified by positional cloning. An excellent example is the authors' recent identification of the first non-lipid-related disease-causing gene, myocyte enhancer specific factor-2A $(M E F 2 A)$, for CAD and $\mathrm{MI}^{2}$ Using a large family with 13 patients who displayed an autosomal dominant inheritance pattern of CAD and MI, Wang et al. successfully identified a significant linkage to $\mathrm{CAD} / \mathrm{MI}$ on chromosome 15q26 (LOD score 4.19), the first locus for autosomal dominant CAD and MI (adCAD1). The adCAD1 disease locus contains 93 known or putative genes, and mutational analysis established one of the genes in the region, $M E F 2 A$, as the gene responsible for CAD and MI. A 21 base pair deletion of $M E F 2 A$ results in the deletion of seven amino acids in the MEF2A protein $(\Delta 7 \mathrm{aa})$, and co-segregates with the disease in the family. It reduces the transcriptional activation activity of $M E F 2 A$ by approximately threefold and abolishes the synergistic activation of transcription by MEF2A in combination with the Gallus gallus GATA transcription factor-1 (GATA-1) through a dominant-negative mechanism. Using immunostaining, a strong MEF2A protein signal was detected in cultured endothelial cells and also within the endothelium of coronary arteries, which is a barrier between vessels and blood elements such as the platelets and macrophages that are central to the pathophysiology of CAD. The authors' studies suggest that an early step in the development of CAD/MI may involve deregulation of specific transcriptional programmes in the endothelium. Defective or abnormally developed vascular endothelium will be more susceptible to inflammation and the diapedesis of monocytes, and expose the subendothelial matrix to the genesis of atherosclerotic plaque or thrombosis. Consistent with the authors' hypothesis, microarray analysis of CAD, atherosclerosis and restenosis revealed differential expression patterns of several genes involved in vasculogenesis, angiogenesis and vascular remodelling, including extracellular growth factor-1 (ECGF1) and MMP-9 in the study by Archacki et al., ${ }^{6}$ VEGF receptor 2, JAK-1 and CD31 in the study by Hiltunen et al., ${ }^{7}$ TSP-1 in the study by Zohlnhofer et al., ${ }^{9}$ and $M C P-1$ and $M C P-2$ in the study by Randi et al. ${ }^{8}$ It is anticipated that microarray analysis will be increasingly used in the positional cloning studies for identification of susceptibility genes for complex human diseases.

\section{Expression profiling of ischaemic myocardium in animal models}

A limitation of using human tissues for microarray analysis is that there is a tremendous amount of biological variability. A study of human tissues from the population usually contains patients with several medical problems, taking several medications and with prior risk factors for atherosclerosis. A study using animal models can overcome the problem of biological variability. Although very limited to date, gene expression profiling has been performed on myocardial tissues in several animal models that have been used to provide information on the process of $\mathrm{MI}$ in a controlled setting, enabling the study of the gene expression profile of MI. The precise mechanisms of ischaemic injury to the myocardium secondary to atherosclerosis have not been fully elucidated. With microarray technology, however, one can begin to have a comprehensive overview of the gene expression patterns occurring in the ischaemic heart (Table 2).

Rabbit hearts that were subjected to two five-minute episodes of ischaemia (followed by five minutes of reperfusion) and then to five hours of additional reperfusion identified 35 genes that were differentially expressed. ${ }^{29}$ A strong upregulation of mitogen-activated protein kinase-activated protein kinase-3 (MAPKAPK-3) was identified. It was inferred that this gene has a protective mechanism against cell injury, as a related gene, MAPKAPK-2, is known to be atheroprotective. ${ }^{30}$

Similarly, the same group studied the same model of ischaemia in rat hearts subjected to a 20-minute transient episode of ischaemia followed by four hours of reperfusion. ${ }^{31}$ The purpose of the study was to determine whether activation of protective genes takes place within four hours following a brief episode of ischaemia, mimicking angina pectoris. ${ }^{31}$ Ischaemia led to strong upregulation of mRNA transcripts for heat shock proteins 70, 27, 105, 86 and $40 \mathrm{kDa}, V E G F$, brain-derived neurotrophic factor, plasminogen activator inhibitor-1, activating transcription factor 3, B-cell translocation gene 2 and growth arrest and DNA damage inducible 45 alpha protein. The study demonstrated that a rapid onset 'genetic reprogramming' occurs during a brief episode of ischaemia and can be characterised as protective in nature. 
Table 2. Expression profiling of ischaemic myocardium in animal models.

\begin{tabular}{|c|c|c|}
\hline Target tissue & Experimental treatment & Number of genes affected \\
\hline Rabbit heart ${ }^{29}$ & $\begin{array}{l}\text { Two five-minute episodes of ischaemia } \\
\text { followed by five hours of reperfusion }\end{array}$ & Strong upregulation of MAPKAPK-3 \\
\hline Rat hearts ${ }^{30,31}$ & $\begin{array}{l}\text { 20-minute episode of ischaemia } \\
\text { followed by four hours of reperfusion }\end{array}$ & $\begin{array}{l}\text { Significant upregulation of } \\
\text { HSP-27 and } 70\end{array}$ \\
\hline $\begin{array}{l}\text { Rat in vivo myocardial } \\
\text { infarction model }{ }^{32}\end{array}$ & Permanent coronary occlusion & 73I differentially expressed genes \\
\hline Rats' hearts ${ }^{33}$ & $\begin{array}{l}\text { Administration of angiotensin-converting } \\
\text { enzyme ( } A C E) \text { inhibitor }\end{array}$ & $\begin{array}{l}37 \text { genes clustered into II functional } \\
\text { groups, ACE inhibition after } \\
\text { myocardial infarction } \\
\text { inhibits cardiac hypertrophy }\end{array}$ \\
\hline Rats' hearts ${ }^{34}$ & $\begin{array}{l}\text { Ligation of the left anterior } \\
\text { descending coronary artery }\end{array}$ & $\begin{array}{l}\text { Expression of genes associated with a } \\
\text { foetal transcription programme }\end{array}$ \\
\hline
\end{tabular}

Stanton et al. studied an in vivo rat MI model by causing a permanent coronary occlusion. ${ }^{32}$ On a microarray with 4,000 probes, they found a total of 731 genes differentially expressed during the 16-week experimental period from two regions of the heart, the left ventricular free wall and the interventricular septum. Upregulated genes included those encoding atrial natriuretic peptide (ANP), sarcoplasmic/endoplasmic reticulum $\mathrm{Ca}^{2+-}$ ATPase, collagen, fibronectin, decorin, fibulin, tissue inhibitor of metalloproteinase-3, fibrillin, laminin, secreted protein acidic and rich in cysteine (SPARC) and osteoblastspecific factor-2. These genes were classified as belonging to a remodelling pathway in the post-MI period. The functional clustering of the gene list showed that the majority of the upregulated genes were classified as cytoskeletal and extracellular matrix (ECM) proteins, while downregulated genes were classified as contractile proteins or fatty acid metabolism-related genes, suggesting a profound change in the energy-generating processes in the ischaemic and then injured myocardial tissue.

In the setting of MI, the angiotensin-converting enzyme inhibitor, captopril, was administered to rats for eight weeks after ligation of their left coronary artery. ${ }^{33}$ In control animals, there was an increased expression of collagen I and III, thrombospondin-4, lysyl oxidase, fibronectin and biglycan eight weeks after MI. There was also upregulation of components of the complement pathways and lipopolysaccharide binding proteins and VCAM-1. The downregulation of fatty acid metabolising enzymes was also documented. With captopril treatment, there was a downregulation of hypertrophy-related genes such as TGF- $\beta_{3}$ and insulin-like growth factor binding protein- 6 . These results indicate that pharmacological treatment in the post-MI period can have an impact on gene expression. Many genes were not affected, however, suggesting the need for more novel forms of therapy to alter ischaemic damage after an MI.

Finally, another rat model employed to study gene expression in the myocardium, induced with the ligation of the left anterior descending (LAD) coronary artery, documented gene expression after 24 hours. ${ }^{34}$ Several genes differentially expressed included genes associated with cardiac muscle development such as the cell cycle regulator $p 18 i n k 4$ and the structural proteins, $\alpha$-myosin heavy chain $(\alpha-M H C)$ and fetal myosin alkali light chain (MLC). Expression of early growth response factors Egr-1 and Egr-3 were upregulated by ischaemia, whereas there was a downregulation of GST. Other stress responses to ischaemia included an induction in the expression of the apoptosis regulator Bax, which may contribute to cell death. This gene list may represent a balance between the cardioprotective and degenerative processes that accompany myocardial ischaemia.

In summary, microarrays have been utilised to understand the consequences of atherosclerosis, which can abruptly cut off the supply of blood and oxygen to the myocardium. The microarray enables investigators to look at a comprehensive overview of genetic changes and may stimulate the development of pharmacological therapy to alter the processes involved in the consequences of MI. It is interesting to note that several genes were identified by both the human and animal model studies (genes for $70 \mathrm{kDa}$ heat shock protein, fibronectin, VCAM-1 and GST), suggesting that microarray analysis of animal models is appropriate for some aspects of the characterisation of human diseases.

\section{Expression profiling of endothelial cells}

The endothelial cell layer of an artery is the first strategic location for the initiation of atherosclerosis. Dysfunction and/or injury of endothelial cells play an important role in atherogenesis. ${ }^{2}$ The endothelium has many functions for example, regulation of tone, coagulation and 
Table 3. Expression profiling of endothelial cells (ECs).

\begin{tabular}{|c|c|c|}
\hline Target tissue & Experimental treatment & Number of genes affected \\
\hline Aortic $\mathrm{EC}^{36}$ & Disturbed flow and steady laminar flow & 100 \\
\hline Coronary artery ${ }^{38}$ & Oxidised low-density lipoprotein & 78 \\
\hline Coronary artery ${ }^{40}$ & Infection with Chlamydia pneumoniae & 268 \\
\hline Coronary artery ${ }^{46}$ & Homocysteine & 600 \\
\hline Coronary artery ${ }^{48}$ & Nicotine & 4 \\
\hline Umbilical vein ${ }^{49}$ & $\mathrm{BO}-653$, probucol and bento(h)quinoline (BHQ) & 17 \\
\hline Smooth muscle cells (SMCs) from plaque ${ }^{50}$ & SMCs + tumour necrosis factor (TNF)- $\alpha$ & 5 \\
\hline Umbilical vein ${ }^{30}$ & Interleukin-I $\beta$ and TNF- $\alpha$ & $209 \mathrm{EC}+39$ in SMCs \\
\hline
\end{tabular}

fibrinolysis - and it secretes several substances. Expression profiling has been performed for endothelial cell lines to study the impact of oxidised low-density lipoprotein (LDL), regulators of inflammation (tumour necrosis factor- $\alpha$ [TNF- $\alpha]$, IL-1 $\beta$ ), infection with Chlamydia pneumoniae (CP), antioxidants, homocysteine and differential patterns of blood flow.

It is hypothesised that areas of the vascular system with turbulent flow are more likely to develop atherosclerotic plaques than are regions with laminar blood flow. ${ }^{35}$ Expression profiling was used to examine the differential expression of genes in human aortic endothelial cells (HAECs) that were exposed to these two conditions (Table 3). ${ }^{36}$ In total, more than 130 genes were induced by turbulent flow as compared with laminar flow. Approximately 50 per cent of the genes surveyed did have a detectable expression at baseline, but at two hours 3-8 per cent of the expressed genes were upregulated, and by 24 hours 14.2 per cent - or 50 genes — were downregulated. The study demonstrated that changes in flow serve as a distinct biomechanical stimulus which has a profound impact upon the gene expression profile of HAEC in vitro.

LDL is well established as contributing to the generation of atherosclerosis. Oxidation of LDL is a key event associated with endothelial cell injury, by leading to the expression of endothelial cell receptors that bind to inflammatory molecules. ${ }^{37}$ Primary human umbilical vein endothelial cells (HUVECs) were exposed to oxidised LDL for six hours. ${ }^{38}$ Of the 588 genes evaluated, 78 genes displayed a greater than twofold change in expression levels: 57 genes were upregulated and 21 genes were downregulated in response to the oxidised LDL. Oxidised LDL significantly affected the expression of genes encoding transcription factors, cell receptors, adhesion molecules, ECM proteins and enzymes involved in cholesterol metabolism. It is interesting to note that expression of retinoic acid receptor- $\beta(R X R-\beta)$ was upregulated in both the turbulent flow and oxidised LDL studies.

Gene expression has been documented in endothelial cells infected with pathogens such as human cytomegalovirus (HCMV) or CP. These pathogens are linked to the develop- ment of vascular disease, including atherosclerosis, ${ }^{39}$ yet the role of pathogens in vasculopathies has been controversial. Expression profiling has identified mechanisms by which CP alters coronary artery endothelial cells. ${ }^{40}$ Twenty of 268 genes on the array were upregulated in human endothelial cells in response to $\mathrm{CP}$, suggesting that $\mathrm{CP}$ infection does not lead to a generalised response in gene expression. Genes coding for cytokines (IL-1), chemokines (MCP-1 and IL-8) and cellular growth factors (heparin-binding epidermal-like growth factor, basic fibroblast growth factor (FGF) and PDGF- $\beta$ chain) were the most prominently upregulated in response to the atypical bacteria. Additionally, increases in the expression of genes coding for intracellular kinases and cell surface receptors with signal transduction activities were observed. Time course experiments showed that mRNA levels were upregulated within two hours following infection.

Novel growth factor genes were also identified and included $\beta$-FGF, HBGF, PDGF- $\beta$ and activin $A$. $\beta$-FGF suggested a pathway in common with endothelial cells and SMCs. HBGF is a growth factor synthesised by endothelial cells which can act as a potent mitogen for the proliferation of SMCs. ${ }^{41}$ Similarly, PDGF- $\beta$ not only has SMC growthpromoting activity but is also associated with neointimal proliferation of SMCs ${ }^{42}$ PDGF- $\beta$ is also a growth factor accessory molecule that modulates the activity of specific growth factors. ${ }^{42}$ Activin A, or erythroid differentiation protein, has been shown to modulate monocyte/macrophage function, including immunological activation of monocytes ${ }^{43}$ and the induction of MMP-2. ${ }^{44} \mathrm{CP}$ induced the expression of E-selectin, ICAM-2 and VCAM-1 two hours after infection, yet returned to basal levels by 24 hour post-infection; ${ }^{45}$ these genes were also upregulated in response to oxidised LDL. E-selectin and VCAM-1 were also upregulated in the endothelial cells exposed to laminar or disturbed flow. These results identify the response of endothelial cells to CP by defining the list of CP-inducible genes and provide new insights into potential mechanisms of atherogenesis from these intracellular bacteria. 
Several other factors directly alter gene expression in endothelial cells. Elevated homocysteine levels have been identified as a risk factor for CAD and have been shown to alter gene expression in endothelial cells. ${ }^{46}$ Using the cardiovascular cDNA microarray approach, the expression of 600 genes in endothelial cells was screened and a subset was identified and considered to be modulated by homocysteine. ${ }^{47}$ They were clustered according to the function of the encoded proteins, such as: endothelial motility, signalling and lipid metabolism. Similarly, oligonucleotide arrays were used to identify gene expression in endothelial cells exposed to nicotine, the major constituent of cigarette smoke. ${ }^{48}$ The most significant changes in gene expression found were the upregulation of proteins in the inositol phospholipid pathway, namely phosphatidylinositol phosphate kinase and diacylglycerol kinase. Changes were also detected for transcription factors, cAMP response element binding protein and nuclear factor (NF)-kappa-B.

Takabe et al. examined gene expression in endothelial cells exposed to BO-653, probucol and bento(h)quinoline (BHQ) — which act as free-radical scavenging antioxidants. ${ }^{49}$ These agents were initially developed as anti-atherosclerotic medications. Among 6,416 genes, 17 genes — including those encoding mitochondrial proteins and proteins related to oxidative stress responses - were induced more than threefold by these three drugs. By contrast, genes of three subunits of the proteosome (PSMA2, PSMA3, PSMA4) were downregulated. The gene coding for the cytochrome P-450 1A1 isozyme pathway, a drug metabolising phase I enzyme, was expressed only by BHQ treatment.

Cultures of coronary artery endothelium and SMCs derived from a single coronary artery have been exposed to IL-1 $\beta$ and TNF- $\alpha$, potent stimulators of inflammation. ${ }^{50}$ The most noticeable difference between the cell types was a considerable greater magnitude and complexity of the transcriptional response in the endothelial cells. Among the 209 regulated genes in the endothelium, 99 were not previously linked directly to atherosclerosis including those that had been associated with leukocyte function (eg, IL-7 receptor, EBI-3 receptor) and others related to antiviral and antibacterial defense (eg, oligoadenylate synthetase, LMP7, toll-like receptor 4, complement component 3). In addition, 43 genes likely to participate in signal transduction (eg IL-18 receptor, STK2 kinase, STAF50, ANP receptor, VIP receptor, $R A C-3, I F P-35)$ were expressed. This provides evidence that a major effect of TNF- $\alpha$ and IL-1 $\beta$ is to alter the potential of the endothelial cell to respond to various other external stimuli.

In summary, multiple pathways are altered in endothelial dysfunction. Expression profiling has documented the alterations in expression of groups of genes by many common agents including laminar flow, infectious agents such as CP and toxic agents like homocysteine, oxidised LDL and nicotine. Alteration of the function of endothelial cells may serve as the first strategic location for halting the cascade of events that may follow modification of gene expression in these cells. Each experimental protocol discussed above elicited an alteration in the expression of a unique cluster of genes. Although most genes were not found to be common among the studies, this may be attributed to the unique response of the endothelial cell under the various conditions. Nevertheless, this may provide further medical strategies and targets for downregulating the inflammatory response which ultimately leads to atherosclerosis.

\section{Expression profiling of vascular SMCs}

The proliferation, migration and invasion of SMCs throughout a coronary artery make a significant contribution to atherosclerosis. Late occlusion of autologous saphenous vein grafts (SVGs) is due to medial and neointimal thickening secondary to migration and proliferation of SMCs and the subsequent formation of atherosclerotic plaques. This process is the main cause of restenosis after percutaneous transluminal coronary angioplasty (PTCA). Understanding SMC proliferation may provide insights into the pathogenic mechanisms of CAD, as well as restenosis after PTCA. Expression profiling of SMCs has identified alterations in gene expression that may be related to the transition of quiescent, contractile SMCs to proliferative SMCs.

Human vascular SMCs were exposed to iloprost, a prostacyclin $\left(\mathrm{PGI}_{2}\right)$ analogues which activates cyclic adenosine $3^{\prime}, 5^{\prime}$ monophosphate signalling, which is associated with maintaining SMCs in a quiescent state (Table 4). ${ }^{51} \mathrm{PGI}_{2}$ is known to be atheroprotective, as it has been shown to exert many effects such as vasodilation, inhibition of platelet aggregation and modulation of cholesterol metabolism, ${ }^{52}$ as well as preventing SMC proliferation and migration. ${ }^{53,54}$ A total of 83 genes were differentially expressed six hours after iloprost exposure. Several of these genes account for the atheroprotective response to iloprost. Mitogen activated protein (MAP) kinase phosphatase-1 (MKP-1) has been regarded as a critical counteracting factor for several transcription factors (p38, c-Jun-N-terminal kinase [JNK], extracellular-signal related/regulated kinase [ERK]), leading to the downregulation of stimuli inducing the proliferation of SMCs. ${ }^{55}$ The zinc finger protein, hEZF, is associated with growth arrest, as it has been shown to inhibit DNA synthesis in fibroblasts overexpressing this gene. ${ }^{56}$ The gene, Cyr61, was found to be downregulated by iloprost. This gene plays a role in mediating cell adhesion and migration and augments growth factor-induced DNA synthesis in fibroblasts. ${ }^{57}$ Other critical genes include: has 2 (of uncertain physiological consequence), stanniocalcin (cell protection against ischaemia ${ }^{58}$ ), plasminogen activator inhibitor-1 (its downregulation may enhance fibrinolytic activity ${ }^{59}$ ), MCP-1 (its downregulation may prevent monocyte attachment to $\mathrm{SMCs}^{60}$ ), heme oxygenase-1 (inhibits SMC proliferation ${ }^{61}$ ) and COX-1 (promotes the synthesis of prostaglandins and thus is a positive autoregulatory 
Table 4. Expression profiling of smooth muscle cells (SMCs).

\begin{tabular}{|c|c|c|}
\hline Target tissue & Experimental design & Number of genes affected \\
\hline Human vascular SMCs ${ }^{50}$ & Exposure of cells to iloprost & 83 \\
\hline SMCs from coronary artery ${ }^{63}$ & Quiescent and invasive SMCs & 47 \\
\hline Human aortic SMCs ${ }^{64}$ & Exposure to tumour necrosis factor- $\alpha$ & Focus on eotaxin and CCR3 receptor \\
\hline Saphenous vein grafts ${ }^{68}$ & Comparison with ungrafted veins & 6 \\
\hline Human aorta ${ }^{70}$ & $\alpha$-Tocopherol treatment & Focus on connective tissue growth factor \\
\hline Arterial SMCs ${ }^{75}$ & Butyrate & 58 \\
\hline
\end{tabular}

mechanism for enhancing prostaglandin levels ${ }^{62}$ ). Downregulation of MCP-1 and COX-1 was identified in atherosclerotic plaques from human patients with unstable angina. ${ }^{8}$

Microarray analysis using 558 cardiovascular-associated genes identified 47 genes differentially expressed in proliferating and non-proliferating human arterial SMCs. ${ }^{63}$ Most of the genes in the study were associated with the ECM and cell motility. The main gene groups identified included matrixorganising proteins, ECM proteins, cell adhesion proteins, and extracellular communication and cytoskeleton motility proteins. Genes previously associated with SMC migration and invasion, such as those coding for tissue inhibitor of metalloproteinases (TIMP)-2, TIMP-3 and MMP-3, were confirmed by the array data. Reduced expression of several cytoskeletal proteins, such as vimentin, fibronectin, cytokeratins and $\beta 1-$ integrin, were downregulated in the invasive phenotype.

Furthermore, angio-associated protein, $\alpha$-E-catenin and brain ANP receptor were downregulated, whereas tissue factor pathway inhibitor-2 (TFPI-2) was strongly upregulated in invasive proliferating SMCs. Consequently, the data document the expression profile of essential genes in SMCs involved in the invasive process.

Microarray analysis with 8,600 genes identified $>20$-fold increases in steady-state eotaxin mRNA. Moreover, follow-up immunohistochemical studies with tissue samples from seven non-diseased and 14 atherosclerotic arteries demonstrated overexpression of eotaxin protein and its receptor, CCR3, in cultured human aortic SMCs treated with TNF- $\alpha$ (which induces vascular inflammation), whereas their expression was negligible in normal vessels. ${ }^{64}$ This was the first study to report the expression of eotaxin by human atheroma. While this was known to be a potent eosinophil chemoattractant and activator, ${ }^{65,66}$ no eosinophils were identified in the target tissue. Similarly, CCR3 had previously been observed in macrophages, mast cells, neutrophils and endothelial cells in endobronchial biopsies of the atopic asthmatic lung. ${ }^{67}$ The implications of the study by Haley et al. are that TNF- $\alpha$ may recruit and activate macrophages and mast cells through the CCR 3 receptor. ${ }^{64}$ This study may lead to the generation of either eotaxin- or CCR3-null mice, which might be resistant to atherogenesis.
In addition to SVGs being used for coronary artery bypass grafting, left and right internal mammary arteries have also been used. ${ }^{68}$ The SVG is the standard conduit for coronary artery bypass grafting to all areas of the heart except the LAD coronary artery. Accelerated atherosclerosis occurs in venous conduits such that during the first year after bypass surgery, 15 per cent of vein grafts occlude; between one and six years, the graft attrition rate is $1-2$ per cent per year; and between six and ten years, it is 4 per cent per year. ${ }^{69}$ Thus, within the first decade of bypass surgery, most bypass grafts will be occluded or significantly diseased. A major component of this occlusion is the proliferation of SMCs. Differentially expressed genes in the saphenous vein have been documented and correlate with expected gene expression patterns, including upregulation of c-Jun and CDK-10. In addition, previously unidentified gene expression patterns were detected, such as the upregulation of HSP-70, fibronectin-1, erbB-3 proto-oncogene and c-myc.

The effect of $\alpha$-tocopherol treatment on gene expression in human aortic SMCs has been studied because it may accelerate wound repair and tissue regeneration during atherosclerosis. ${ }^{70}$ This medication is also often recommended because of its antioxidant properties. ${ }^{71}$ The expression of the connective tissue growth factor (CTGF) gene was induced by $\alpha$-tocopherol 1.8 fold. It was hypothesised that this gene is involved in normal repair processes and is permanently overexpressed in pathological events. ${ }^{70} \alpha$-tocopherol may either stimulate the synthesis of CTGF or interfere with the effect of TNF- $\alpha$ on downregulation of this gene.

cDNA array technology has been utilised to unravel the molecular basis of the antiproliferative effect of butyrate on vascular SMCs. Butyrate is a natural fatty acid ester which has been shown to inhibit SMC proliferation in in vitro cell culture systems. ${ }^{72}$ It is derived from the microbial metabolism of dietary fibre in the colon, where it is produced in high levels. ${ }^{73}$ It can function as an anti-inflammatory agent by suppressing intestinal inflammation, ${ }^{74}$ and may alter gene expression by reversibly inhibiting histone deacetylase, causing the hyperacetylation of histones and thereby leading to selective changes in gene expression. ${ }^{73}$ To assess the involvement of gene expression in butyrate-inhibited vascular SMC proliferation, proliferating vascular SMCs were exposed to butyrate. ${ }^{75}$ 
Table 5. Expression profile of inflammatory cells.

\begin{tabular}{|lll|}
\hline Target tissue & Experimental design & Number of genes affected \\
\hline Macrophages $^{76}$ & Oxidised low density lipoprotein & 268 \\
\hline Human monocytic leukaemia cell line & Lipopolysaccharide & 57 \\
\hline Macrophages $^{78}$ & Exposure to copper & 7 \\
\hline Macrophages $^{80}$ & Exposure to arsenic & 62 \\
\hline THP-I cells & & 3 \\
\hline Macrophages & & \\
\hline
\end{tabular}

A total of 111 genes exhibiting moderate (two- to fivefold) to strong ( $>$ fivefold) differential expression were identified. Analysis of these genes indicates that butyrate treatment mainly alters the expression of four different functional classes of genes, including 43 genes implicated in cell growth and differentiation, 13 genes related to stress response, 11 genes associated with vascular function and eight genes normally present in neuronal cells. cDNA expression profiles indicate that butyrate-inhibited vascular SMC proliferation involves a combined action of a proportionally large number of both positive and negative regulators of growth, which ultimately causes growth arrest of vascular SMCs. ${ }^{75}$ For example, the downregulated genes included $p R b$ (required for $\mathrm{G} 1$ to $\mathrm{S}$ phase entry), S phase-specific mus musculus podocan (PCAN), G2/M phase-specific cyclinB1 and $c d c 2$, and $p 55 c d c$. The downregulation of these critical positive regulators of cell cycle progression indicates that butyrate exerts its antiproliferative effect by altering key positive regulators of all phases of cell cycle progression. Furthermore, butyrate also appeared to block SMC proliferation by upregulating negative regulators of cell growth or differentiation inducers such as p21waf1, p14INK4B/ $p 15 I N K 5 B$ and clusterin. Consequently, the identification of the molecular mechanisms of butyrate-inhibited proliferation is important, not only to understand the molecular basis of butyrate-induced SMC proliferation, but also because of its potential use as a therapeutic agent to prevent restenosis of arteries in humans.

In summary, smooth muscle cell proliferation contributes to the formation of atherosclerotic lesions and restenosis after angioplasty, and microarray studies have identified multiple genes that are involved in this process. Understanding the molecular mechanisms involved may provide novel insights into pharmacological approaches to preventing SMC migration.

\section{Expression profiling of inflammatory cells}

Inflammatory cells play an important role in the development of CAD. First, monocyte recruitment is a key event in the formation of the earliest vascular lesion, the fatty streak. Secondly, macrophage uptake of modified LDLs via scavenger receptors gives rise to foam cells in the atheroma, and these secrete growth factors, cytokines and inflammatory mediators that influence the growth and development of other cell types within the atherosclerotic lesion, generating plaques. Microarrays have been used to profile gene expression changes in the inflammatory cells in relation to the formation of atherosclerotic lesions.

Gene expression of macrophages has been analysed using microarrays containing approximately 16,000 human cDNAs (Table 5). ${ }^{76}$ The human monocytic leukaemia cell line (THP-1) was treated with oxidised LDL. The cells were then activated by treatment with lipopolysaccharide (LPS), and RNA was harvested at zero, one and six hours after LPS addition. Oxidised LDL treatment affected the expression of 57 of 127 genes in macrophages. Among them are genes that code for potent intracellular and extracellular signalling molecules such as NF- $\mathrm{BB}, \mathrm{A} 20$ and numerous cytokines and chemokines. Oxidised LDL pretreatment resulted in a significant change in LPS-induced NF- $\mathrm{kB}$ activation. Some of the oxidised LDL effects were mediated by the nuclear receptors RXR and peroxisomal proliferator-activated receptor- $\gamma$.

To further define the mechanisms by which LDL particles affect macrophages and foam cells, a large-scale gene expression analysis of cholesterol-loaded macrophages was carried out. ${ }^{77}$ Oxidised LDL-treated and time-matched control untreated cells were hybridised to microarrays containing 9,808 human genes. Two hundred and sixty-eight genes were found to be differentially expressed at least twofold at one or more time points. These patterns of regulation were classified into seven clusters. Shiffman et al. identified patterns of gene expression of known and novel molecular components of the cellular response that are implicated in the growth, survival, migratory, inflammatory and matrix remodelling activity of vessel wall macrophages. ${ }^{77}$ The data indicate that oxidised LDL loading of THP-1 cells did not elicit any measurable immediately transcriptional response from the genes studied until day 4. The novel and most highly upregulated genes identified were: DSCR1, liver and activation-regulated chemokine 
(LARC)/MIP-3 $\alpha, C D 73 / 5^{\prime}$-nucleotidase, epithelial membrane protein-1, uridine phosphorylase and two expressed sequence tags (ESTs). The incidence of these genes indicates that the previously published data on oxidised LDL loading of macrophages only partially describes the changes that occur in some inflammatory cells. The most highly downregulated genes included promoters of the anti-microbial potential of macrophages (carbonic anhydrase, cytochrome b-245, RNase A2, CD64) and three involved in cell cycle progression or synthesis of precursors involved in cell division (genomic oryza saliva protein [GOS2] protein, thymidylate synthetase, lamin B1).

Similarly, DNA microarrays were used to define the changes in gene expression profile in response to copper exposure of human macrophages. ${ }^{78}$ Serum copper has been shown to be associated with cardiovascular disease (a 3.5-fold increased risk of acute $\mathrm{MI}$ ) but its mechanism of action has not been identified. $^{79}$ The results showed that expression of 91 genes were altered. Copper increased the expression of seven cholesterogenic genes (3-hydroxy-3-methylglutaryl coenzyme A synthase, isopentenyl pyrophosphate isomerase, squalene synthase, squalene epoxidase, methyl sterol oxidase, H105e3 mRNA and sterol-C5-desaturase) and the gene encoding the $L D L$ receptor, and decreased the expression of CD36 and lipid-binding proteins. Thus, copper activates cholesterogenic genes in macrophages involved in LDL uptake and de novo cholesterol biosynthesis. This leads to lipid accumulation in the inflammatory cells and thus the arterial wall.

Gene expression was also studied in lymphocytes exposed to arsenic, which is associated with an increased risk for vascular disease. ${ }^{80}$ Patients were exposed to low, intermediate or high levels of arsenic as determined by monitoring serum levels. A total of 62 genes showed a significant difference in the intermediate and high levels of blood arsenic, as compared with low levels. These genes included those encoding $I L-1 \beta$, IL-6, chemokine C-C motif ligand2/MCP-1, chemokine C-X-C motif ligand $1 /$ growth-related oncogene- $\alpha$, chemokine $C-X-C$ motif ligand 2 /growth-related oncogene- $\beta, C D 14$ antigen and MMP- 1 .

The effect of biomechanical forces on macrophage functions in atherosclerosis was determined by microarrays with 1,056 genes. ${ }^{81}$ Mechanical deformation at $1 \mathrm{~Hz}$ was applied to a thin transparent membrane on which the cells were cultured. This induced only three genes to more than 2.5-fold higher expression at three and six hours: prostate apoptosis response- 4 (3.0-fold at three hours, 6.7-fold at six hours), IL-8 (4.3-fold at six hours) and the immediate-early response gene, IEX-1 (2.6fold at six hours). IL- 8 may be important in the initiation and amplification of inflammation and angiogenesis in atherosclerosis, because it is chemotactic for vascular SMCs, T lymphocytes and neutrophils. ${ }^{82}$ It also triggers the firm adhesion of monocytes to the vascular endothelium. ${ }^{83}$ IEX-1 is an NF- $\mathrm{KB}$-inducible immediate-early gene which inhibits apoptosis. ${ }^{84}$ It may also participate in the differentiation of monocytes/macrophages. Protease-activated receptor-4 (PAR-4) is known to be a widely expressed protein which confers sensitisation to apoptosis-induced insults. ${ }^{85}$ Consequently, Johnstone et al. demonstrated that human monocytic cells respond to mechanical deformation with induction of immediate-early and inflammatory genes. This suggests that mechanical stress in vivo, such as that associated with hypertension, may play an important part in atherogenesis and instability of coronary artery plaques through biomechanical effects on vascular macrophages.

Human monocyte-derived macrophages from healthy male and female donors have been exposed to androgen (dihydrotestosterone) in an effort to detect gender-specific changes in gene expression, ${ }^{86}$ as it has already been established that there is a gender difference in the severity of disease, with men having more severe coronary artery disease than women. ${ }^{87}$ In macrophages harvested from males, treatment with androgen resulted in the differential upregulation of 27 genes, whereas none was upregulated in female harvested macrophages. Some of these genes directly related to the process of atherosclerosis, including the upregulation of acyl coenzyme A:cholesterol acyl transferase I and lysosomal acid lipase ( $L A L)$ - which play a role in the delivery of lipoproteins to cells, ${ }^{88}$ caveolin-2, CD40, leukotriene $B 4$ receptor and cadherin-19 (the latter three play a role in inducing cell surface receptors for monocyte attachment ${ }^{89}$ ). Functional studies to complement the microarray results showed a direct clinical correlation with $\mathrm{LAL}$, in that there was a consistent increase in activity with ${ }^{125} \mathrm{I}-\mathrm{AcLDL}$ exposure. ${ }^{88}$ It can be concluded that androgen exposure as it occurs naturally in the male gender is directly responsible for inducing genes associated with the development of atherosclerosis and may account for gender differences in the incidence of CAD.

\section{Expression profiling of CHF}

$\mathrm{CHF}$ is a term used to describe any condition in which the heart is unable to generate an adequate pressure to pump blood throughout the body. This condition causes symptoms such as shortness of breath (dyspnoea), fatigue, weakness and swelling (oedema) of the legs and sometimes in the abdomen (ascites). An estimated 4.8 million Americans have $\mathrm{CHF}^{90}$ and half of all patients diagnosed with CHF will be dead within five years. Each year, there are an estimated 700,000 new cases in the USA. Increasing prevalence, hospitalisations and deaths have made CHF a major chronic condition in the USA. It often occurs as the end stage of cardiac disease, referred to as ischaemic cardiomyopathy (ICM) due to severe CAD. Expression profiling of human cardiac tissues has been employed to identify genes whose expression is linked to CHF, and these studies are summarised below.

Oligonucleotide microarrays were used to profile seven non-failing (NF) and eight failing (F) human hearts with a diagnosis of end-stage dilated cardiomyopathy (DCM) (Table 6). ${ }^{91}$ Of 6,606 genes on the microarray, 103 genes in ten functional groups were differentially expressed between $\mathrm{F}$ 
Table 6. Expression profiling of congestive heart failure (CHF).

\begin{tabular}{|c|c|c|}
\hline Target tissue & Experimental design & Number of genes affected \\
\hline $\begin{array}{l}\text { End-stage dilated } \\
\text { cardiomyopathy }(\mathrm{CM})^{91}\end{array}$ & Failing versus non-failing & 103 \\
\hline End-stage dilated $\mathrm{CM}^{92}$ & Failing versus non-failing & 100 \\
\hline $\mathrm{CM}^{93}$ & $\begin{array}{l}\text { Dilated versus ischaemic } \\
\text { myocardial tissue }\end{array}$ & 192 \\
\hline Human heart $^{94}$ & $\begin{array}{l}\text { Four groups: i) left } \\
\text { ventricle (LV); ii) LV from } \\
\text { failing hearts affected by } \\
\text { dilated CM); iii) LV from failing } \\
\text { hearts affected by ischaemic } \\
\text { CM; iv) right ventricle }\end{array}$ & $\mathrm{I}, 306$ \\
\hline Human heart $^{98}$ & $\begin{array}{l}\text { End-stage ischaemic and } \\
\text { dilated CM }\end{array}$ & $\begin{array}{l}12 \text { (in CHF) } \\
5 \text { (exclusive to CHF) } \\
2 \text { (exclusive to non-CHF) }\end{array}$ \\
\hline Idiopathic dilated $\mathrm{CM}^{101}$ & Pro-apoptotic genes & $\begin{array}{l}\text { Tumour necrosis factor- } \alpha \\
\text { signalling pathway }\end{array}$ \\
\hline Idiopathic dilated $\mathrm{CM}^{102}$ & $\begin{array}{l}\text { Left ventricular assist device } \\
\text { (LVAD) support }\end{array}$ & $\begin{array}{l}\text { I,374 genes were reported as } \\
\text { 'increased' and I,629 as 'decreased' }\end{array}$ \\
\hline End-stage $\mathrm{CHF}^{103}$ & LVAD support & 47 (pre- versus post-LVAD) \\
\hline End-stage $\mathrm{CHF}^{104}$ & LVAD support & $\begin{array}{l}\text { Two distinct groups identifiable } \\
\text { with present or absent LVAD }\end{array}$ \\
\hline End-stage $\mathrm{CHF}^{105}$ & LVAD support & Focus on apelin \\
\hline
\end{tabular}

and NF hearts. In F hearts, $\mathrm{K}$ means clustering revealed two potentially novel pathways associated with up-regulation of atrial natriuretic factor and brain natriuretic peptide and with increased expression of ECM proteins. A dendrogram or genetic profile of the two tissues distinguished two $\mathrm{F}$ hearts with distinct aetiologies (familial and alcoholic cardiomyopathy, respectively). The study demonstrated that there is a unique molecular signature in $\mathrm{F}$ hearts.

Similarly, a 'genomic portrait' of heart failure derived with microarrays was obtained from end-stage DCM using the CardioChip with non-redundant 10,848-element human cardiovascular-based ESTs. ${ }^{92}$ More than 100 transcripts were consistently differentially expressed in DCM $>1.5$-fold (versus pooled NF hearts). $A N P$ was also found to be upregulated in DCM (19-fold compared with NF hearts) as well as numerous sarcomeric and cytoskeletal proteins (eg cardiac troponin, tropomyosin), stress response proteins (eg HSP-40, HSP-70) and transcription/translation regulators (eg CCAAT box binding factor, eIF-1AY). Downregulated genes were classified as cell-signalling channels and mediators, particularly those involved in calcium pathways (calcium/calmodulin-dependent kinase, inositol 1,4,5-trisphosphate receptor and sarcoplasmic reticulum $\mathrm{Ca}^{2+-}$ ATPase [SERCA]). Several novel, cardiacenriched ESTs were also co-expressed. The study demonstrated a common expression pattern among the sets of samples with DCM and documents a gene list that may serve as possible targets for therapeutic intervention specific to cardiac tissue.

Also using patients with either DCM or hypertrophic cardiomyopathy (HCM) at end-stage CHF, Hwang et al. generated a list of predictive markers for these two diseases. ${ }^{93}$ Similar to previous studies, ANP and SERCA were found to be increased and decreased, respectively, and this was consistent in all of the tissues studied. Other genes having the same expression levels in both DCM and HCM tissues included: copper/zinc superoxide dismutase, heat shock protein 90, elongation factor-2, calcium-activated neutral protease, decorin and CD59. Genes found to be differentially expressed between DCM and HCM included atrial myosin alkali light chain, calsequestrin, lipocortin and lumican, which were upregulated, while $m y c$ transcriptional activity and $\beta$-dystrobrevin were downregulated. In total, the study documented 192 genes. As in the previous studies reviewed, ANP and SERCA displayed the same expression patterns consistently in both populations of samples. 
In a study by Steenman et al., the expression profiles of four specific pathophysiological cardiac situations was analysed: i) left ventricle (LV) from NF heart; ii) LV from $F$ heart affected by DCM; iii) LV from F heart affected by ICM; and iv) right ventricle (RV) from F heart affected by DCM or ICM. ${ }^{94}$ Microarrays representing approximately 12,000 human genes were utilised. The authors identified 1,306 genes with a similar expression profile in all four cardiac situations. The upregulation of embryonic myosin alkali light chain-C1 (MLC1emb), calponin and SM22 represented a reversal to developmental gene expression such as occurs in cardiac remodelling and CHF. The expression of smooth muscle myosin heavy chain and smooth muscle $\alpha$-actin represented a dedifferentiation process. Several apoptosis-related genes were identified in F LV and/or RV samples, with CDKN1A showing the most marked activation. Stress-inducible metallothionein was also upregulated; this functions as an antioxidant and inhibits the production of atrial natriuretic factor. ${ }^{95}$ Novel genes included $A F 1 a$, a transmembrane protein, ${ }^{96}$ and $S H 3 B G R$. Relatively few genes were differentially expressed between F LV and F RV samples, yet the most marked difference was found in the gene profiling, an actin-binding protein being implicated in the control of actin polymerisation and cytoskeletal reorganisation. ${ }^{97}$ Finally, no genes were significantly differentially expressed between DCM and ICM F hearts, which indicates that all hearts were clinically in failure.

In a separate study, oligonucleotide arrays have identified specific genes expressed in patients with $\mathrm{CHF}$, screening over 7,000 genes in two NF and two F human hearts with diagnoses of end-stage ICM and DCM. ${ }^{98}$ Genes were categorised into five groups: (a) cytoskeletal and myofibrillar genes (myomesin, non-sarcomeric myosin regulatory light chain-2 [MLC2] and ss-actin); (b) genes responsible for the degradation and disassembly of myocardial proteins (alpha-1-antichymotrypsin, ubiquitin and gelsolin); (c) genes involved in metabolism (ATP synthase alpha-subunit, succinate dehydrogenase flavoprotein [SDH Fp] subunit, aldose reductase and translocator of inner membrane-17 [TIM-17] preprotein translocase); (d) genes responsible for protein synthesis (elongation factor-2 [EF-2], eukaryotic initiation factor-4AII and transcription factor homologueHBZ17); and (e) genes encoding stress proteins ( $\alpha$-B-crystallin and $\mu$-crystallin). The study focused on the novel striated muscle LIM protein-1 (SLIM1) gene as being consistently downregulated in CHF. Although the precise function of SLIM1 has not been determined, it is hypothesised that it may act as a scaffold for interaction between thin filaments and the cytoskeleton, ${ }^{99}$ in a similar way to muscle Lin-11-Isl-1-Mec-3 (LIM) protein (ML). Myosin-like protein $(M L P)$ knockout mice have been shown to develop DCM. ${ }^{100}$ All of the identified genes may contribute to development of the heart failure phenotype and represent compensatory mechanisms to sustain cardiac function in failing human hearts.
Similarly, Steenbergen et al. used DNA microarray profiling to investigate changes in the expression of genes involved in the apoptosis that occurs in human idiopathic DCM hearts that have progressed to CHF. ${ }^{101}$ They documented altered gene expression consistent with a pro-apoptotic shift in the TNF- $\alpha$ signalling pathway. Specifically, they found decreased expression of $T N F-\alpha$ - and $N F-\kappa B$-induced anti-apoptotic genes such as growth arrest and DNA damage-inducible (GADD) $45-\beta$, Flice inhibitory protein (FLIP) and TNF-induced protein 3 (A20) genes. They also observed a significant decrease in the phosphorylation of $\mathrm{Bd}$-accelerating apoptosis (BAD) at Ser-112, which is also consistent with a role for apoptosis in heart failure.

One option for improving left ventricular function in $\mathrm{CHF}$ is the use of a left ventricular assist device (LVAD). The unloading of the F heart with an LVAD can decrease cardiac mass and myocyte size and has the potential to improve contractile function. Several studies have documented changes in gene expression brought about by the presence of an LVAD. The effect of chronic ventricular unloading on myocardial gene expression was compared before and after LVAD support in seven patients with idiopathic DCM and end-stage $\mathrm{CHF}^{102}$ On average, 1,374 genes were reported as 'increased' and 1,629 'decreased' after LVAD support. Upregulated genes included a large proportion of transcription factors, genes related to cell growth/apoptosis/DNA repair, cell structure proteins, metabolism and cell signalling/communication. LVAD support resulted in downregulation of genes coding for cytokines. Similarly, Chen et al. performed transcriptional profiling using a spotted cDNA microarray with 12,814 unique clones on paired samples of LV obtained before and after placement of an LVAD in 11 patients. ${ }^{103}$ The most significantly upregulated gene was the G-protein-coupled receptor APJ, the specific receptor for apelin. Blaxall et al. also examined gene expression, performing oligonucleotide arrays with LV samples from six male patients which were harvested during LVAD placement and at the time of explantation. ${ }^{104}$ These authors documented a significant difference in the corresponding LVAD-mediated regulation of gene expression and were able to distinguish, in a blind manner, patients with different CHF aetiologies.

Finally, microarrays were utilised on paired samples of human tissue from patients with CHF with and without an LVAD. ${ }^{105}$ After several statistical analyses of the data, approximately 85 upregulated genes were identified. The focus of the study was on apelin, which was the most significantly upregulated gene and was localised primarily in the endothelium of the coronary arteries after the mechanical offloading by the LVAD. This finding implies an important paracrine signalling pathway in the $F$ heart. The identification of this gene led to the measurement of serum apelin levels. These were found to be increased in the serum of patients with $\mathrm{F}$ hearts and may serve as a biological marker in patients with $\mathrm{CHF}$. 
In summary, microarray analysis of CHF can reveal the underlying molecular mechanisms regulating hypertrophy and proliferation, as well as apoptosis of cardiomyocytes. These studies revealed the dysregulation of various molecular pathways involved in CHF.

\section{Expression profiling of CHD}

Congenital heart defects account for the largest number of birth defects in humans. ${ }^{4}$ The application of expression profiling in patients with CHD is still in its infancy. To date, only one microarray study has documented gene expression in CHD.

Microarray analysis was carried out in cardiac samples collected during cardiac surgery, from six normal samples and from 55 patient samples with various cardiac defects. ${ }^{106}$ Human Unigene Set-RZPD 2 cDNA arrays with 12,657 known genes were used. The study identified specific molecular signatures for tetralogy of Fallot (TOF), ventricular septal defects (VSDs) and right ventricular hypertrophy $(\mathrm{RVH})$, each of which has a distinct gene expression profile. TOF and RVH were found to be associated with genes of various functional classes, and can be clearly distinguished by different molecular signatures. The TOF signature consists of many genes involved in the cell cycle and cardiac development (eg upregulation of switch nuclear B-site protein [SNIP], $A 2 B P 1$ and KIAA1437, and downregulation of STK33, BRDG1 and TEKT2) and the upregulation of ribosomal proteins S6, L37a, S3A, S14 and L13A. The RVH signature includes genes mainly involved in the stress response, cell proliferation and metabolism - for example, the upregulation of ADD2. VSDs have been associated with a specific signature consisting of downregulation of genes for ribosomal proteins S11, L18A, L36, LPO, L31 and MRPS7, and downregulation of genes involved in cell proliferation, differentiation and apoptosis (eg S-adenosyl-methionine decarboxylase [AMD1], receptor interacting protein serine-threonine kinase-3 [RIPK3], Egl-Nine gene family [EGLN1], human siah binding protein-1 [SIAHBP1], and Armadilla repeat-protein in velo-cardiofacial syndrome $[A R V C F])$. Several ion channel genes, including SLC26A8, SLC16A5, SLC4A7, KCNS2 and KCNN3, were found to be differentially expressed in VSD tissues. The study also identified heart chamber-specific expression of many genes. The human heart consists of two atria and two ventricles. The atria have been found to have higher expression of genes for ECM or actin modulation, such as clevage stimulating factor-3 (CST3) and procollagen $\mathrm{COOH}$-terminal proteinase enhancer protein (PCOLCE), translation factor EEF1A and the DNA helicase RecQ protein-like-4 (REQL4) and a potassium channel subunit KCNIP2. Genes with higher expression in the ventricles encode proteins for cytoskeleton contraction, metabolism-energy turnover and cell cyclegrowth, and include TMP1, human factor H-like protein (FHL1) and the muscle ankyrin repeat protein (ANKRD2).

\section{Conclusions}

The availability of cDNA and oligonucleotide microarrays with several thousand human genes makes it possible to study global changes in gene expression in CAD, CHF and CHD. These studies have identified novel genes and pathways involved in the generation of these diseases at both the organ/ tissue level (coronary arteries, cardiac tissues) and cell level (endothelial cells, vascular SMCs, macrophages). It is important to note that several studies have confirmed the expression of genes previously linked with these disease processes, suggesting that expression profiling with microarrays is a valid approach for identifying gene expression alterations associated with disease. Yet, many more novel genes have also been identified and will serve as a valuable resource for identifying novel pathways involved in the generation of disease. With the continued use of this technology, and an accelerated application to these diseases, we will eventually identify a common group of genes which will be able to serve as markers for these disease processes on a global scale. It is important, however, to note that different studies have identified different sets of genes associated with these diseases. Thus, the microarray results remain to be replicated in an independent set of samples and caution needs to be taken when interpreting these results. In addition, a major limitation of microarray analysis is that it is usually difficult to distinguish whether the identified differential gene expression patterns are the cause or the consequence of the disease. Follow-up studies with transgenic overexpression or knockout of the gene of interest in animal models are needed to solve this issue. Furthermore, microarray analysis is biased to the genes on the arrays and cannot be used to evaluate low-abundant transcripts. Microarray analysis also results in false-positives; it is therefore crucial that results are confirmed using conventional technologies, such as quantitative real-time PCR, quantitative reverse-transcription PCR, Northern blot, Western blot or immunostaining analyses. Finally, the expression level of mRNA does not necessarily reflect the expression of the protein, and the pathogenic mechanism of a disease may involve protein modifications such as phosphorylation and glycosylation. Under these circumstances, proteomics will prove to be a powerful, alternative technology. The first proteomics analysis has been performed for $\mathrm{CAD}$ by the authors of this paper, and the study identified the ferritin light chain as a significant marker for diseased coronary arteries. ${ }^{3}$ It is important to point out that proteomics can analyse far fewer genes than can microarrays, as the resolution of the common two-dimensional gel separation of protein extracts is limited to only a few thousand protein spots. Proteomics also shares some common limitations with microarray analysis; for example, it cannot be used to evaluate low-abundant proteins/genes.

Nevertheless, microarray analysis can generate novel hypotheses relating to the pathologies of these diseases, and further studies with animal models, molecular biology, cell 
biology and biochemistry will validate these hypotheses and provide novel insights into the pathogenesis of disease. These studies will eventually generate novel diagnostic and therapeutic markers, and identify potential drug targets which will serve to bring about more effective management of cardiovascular disease.

\section{Acknowledgments}

This work was supported by grants from NIH/NHLBI (HL65630 and HL66251) and an American Heart Association Established Investigator award to Q.W.

\section{References}

1. Gabbing, M. and Weary, G. (2002), 'An introduction to DNA chips: Principles, technology, application and analysis', ACTA Biochemical Polemical Vol. 48, pp. 615-622.

2. Wang, L., Fan, C., Topol, S.E. et al. (2003), 'Mutation of MEF2A in an inherited disorder with features of coronary artery disease', Science Vol. 302, pp. 1578-1581.

3. You, S.A., Archacki, S.R., Angheloiu, G. et al. (2003), 'Proteomic approach to coronary atherosclerosis shows ferritin light chain as a significant marker: Evidence consistent with iron hypothesis in atherosclerosis', Physiol. Genomics Vol. 13, pp. 25-30.

4. American Heart Association Facts sheet, (2003), www.americanheart.org.

5. Lusis, A.J., Weinreb, A. and Drake, T.A. (1998), 'Genetics of atherosclerosis', In: Topol, E.J. (ed.), Comprehensive Cardiovascular Medicine, Lippincott-Raven, Philadelphia, PA, p 2763.

6. Archacki, S.R., Angheloiu, G., Tian, X.L. et al. (2003), 'Identification of new genes differentially expressed in coronary artery disease by expression profiling', Physiol. Genomics Vol. 15, pp. 65-74.

7. Hiltunen, M.O., Tuomisto, T.T., Niemi, M. et al. (2002), 'Changes in gene expression in atherosclerotic plaques analyzed using DNA array', Atherosclerosis Vol. 165, pp. 23-32.

8. Randi, A.M., Biguzzi, E., Falciani, F. et al. (2003), 'Identification of differentially expressed genes in coronary atherosclerotic plaques from patients with stable or unstable angina by cDNA array analysis', J. Thromb. Haemost. Vol. 1, pp. 829-835

9. Zohlnhofer, D., Klein, C.A., Richter, T. et al. (2001), 'Gene expression profiling of human stent-induced neointima by cDNA array analysis of microscopic specimens retrieved by helix cutter atherectomy: Detection of FK506-binding protein 12 up-regulation', Circulation Vol. 13, pp. $1396-1402$.

10. Faber, B.C., Cleutjens, K.B., Niessen, R.L. et al. (2001), 'Identification of genes potentially involved in rupture of human atherosclerotic plaques', Circ. Res. Vol. 89, pp. 547-554.

11. Wuttge, D.M., Romert, A., Eriksson, U. et al. (2001), 'Induction of CD36 by all-trans retinoic acid: retinoic acid receptor signaling in the pathogenesis of atherosclerosis', FASEB J. Vol. 15, pp. $1221-1223$.

12. Ogg, S.L., Dobbie, L., Smith, A.J.H. et al. (2000), 'Ablation of the mouse butyrophilin gene by homologous recombination disrupts the regulated secretion of milk-lipid droplets from mammary epithelial cells', Mol. Biol. Cell Vol. 11, pp. 1535

13. Yamashita, D.S. and Dodds, R.A. (2000), 'Cathepsin K and the design of inhibitors of cathepsin K', Curr. Pharm. Des. Vol. 6, pp. 1-24.

14. Tung, W.S., Lee, J.K. and Thompson, R.W. (2001), 'Simultaneous analysis of 1176 gene productions in normal human aorta and abdominal aortic aneurysms using a membrane-based complementary DNA expression array', J. Vasc. Surg. Vol. 34, pp. 143-150.

15. Stocco, D.M. (2002), 'Clinical disorders associated with abnormal cholesterol transport: Mutations in the steroidogenic acute regulatory protein', Mol. Cell. Endocrinol. Vol. 91, pp. 19-25.
16. Baytel, D., Shalom, S., Madgar, I. et al. (1998), 'The human Pim-2 proto-oncogene and its testicular expression', Biochim. Biophys. Acta. Vol. 1442, pp. 312-313.

17. Schindler, C., Fu, X.Y., Improta, T. et al. (1992), 'Proteins of transcription factor ISGF-3: One gene encodes the 91- and 84-kDa ISGF-3 proteins that are activated by interferon alpha', Proc. Natl. Acad. Sci. USA Vol. 89, pp. 7836-7839.

18. Kidd, P.M. (1997), 'Glutathione: Systemic protectant against oxidative and free radical damage', Alt. Med. Rev. Vol. 2, pp. 155-176.

19. Reddy, K.B. and Howe, P.H. (1993), 'Transforming growth factor beta 1-mediated inhibition of smooth muscle cell proliferation is associated with late G1 cell cycle arrest', J. Cell. Physiol. Vol. 156, pp. $48-55$

20. Huynh, H.T., Larsson, C., Narod, S. et al. (1995), 'Tumor suppressor activity of the gene encoding mammary-derived growth inhibitor', Cancer Res. Vol. 55, pp. 2225-2231.

21. Huynh, H., Alpert, L. and Pollak, M. (1996), 'Silencing of the mammary-derived growth inhibitor (MDGI) gene in breast neoplasms is associated with epigenetic changes', Cancer Res. Vol. 56, pp. 4865-4870

22. Göthel, S.F. and Marahiel, M.A. (1999), 'Peptidyl-propyl cis-trans isomerases, a superfamily of ubiquitous folding catalysts', Cell. Mol. Life Sci. Vol. 55, pp. 423-436.

23. Gallo, R., Padurean, A., Jayaraman, T. et al. (1999), 'Inhibition of intimal thickening after balloon angioplasty in porcine coronary arteries by targeting regulators of the cell cycle', Circulation Vol. 99, pp. 2164-2170.

24. Faber, B.C., Heeneman, S., Daemen, M.J. et al. (2002), 'Genes potentially involved in plaque rupture', Curr. Opin. Lipidol. Vol. 13, pp. $545-552$.

25. Greenberg, A.S., Egan, J.J., Wek, S.A. et al. (1991), 'Perilipin, a major hormonally regulated adipocyte-specific phosphoprotein associated with the periphery of lipid storage droplets', J. Biol. Chem. Vol. 266, pp. $11341-11346$.

26. Blanchette-Mackie, E.J., Dwyer, N.K., Barber, T. et al. (1995), 'Perilipin is located on the surface layer of intracellular lipid droplets in adipocytes', J. Lipid Res. Vol. 36, pp. 1211-1226.

27. Souza, S.C., de Vargas, L.M., Yamamoto, M.T. et al. (1998), 'Overexpression of perilipin A and B blocks the ability of tumor necrosis factor alpha to increase lipolysis in 3T3-L1 adipocytes', J. Biol. Chem. Vol. 273, pp. 24665-24669.

28. Braseaemle, D.L., Rubin, B., Harten, I.A. et al. (2000), 'Perilipin A increases triacylglycerol storage by decreasing the rate of triacylglycerol hydrolysis', J. Biol. Chem. Vol. 291, pp. 1304-1351.

29. Simkhovich, B.Z., Abdishoo, S., Poizat, C. et al. (2002), 'Gene activity changes in ischemically preconditioned rabbit heart: Gene discovery array study', Heart Dis. Vol. 4, pp. 63-69.

30. Maulik, N., Watanabe, M., Zu, Y.L. et al. (1996), 'Ischemic preconditioning triggers the activation of MAP kinases and MAPKAP kinase 2 in rat hearts', FEBS Lett. Vol. 396, pp. 233-237.

31. Simkhovich, B.Z., Marjoram, P., Dow, J. et al. (2002), 'A brief episode of myocardial ischemia in the rat turns on novel sets of genes', J. Am. Coll. Cardiol. Vol. 39, pp. 283A.

32. Stanton, L.W., Garrard, L.J., Damm, D. et al. (2000), 'Altered patterns of gene expression in response to myocardial infarction', Circ. Res. Vol. 86, pp. 939-945.

33. Jin, H., Yang, R., Awad, T.A. et al. (2001), 'Effects of early angiotensinconverting enzyme inhibition on cardiac gene expression after acute myocardial infarction', Circulation Vol. 103, pp. 736-742.

34. Lyn, D., Liu, X., Bennet, N.A. and Emmet, N.L. (2000), 'Gene expression profile in mouse myocardium after ischemia', Physiol. Genomics Vol. 2, pp. 93-100.

35. Gimbrone, Jr, M.A., Topper, J.N., Nagel, T. et al. (2000), 'Endothelial dysfunction, hemodynamic forces, and atherogenesis', Ann. N. Y. Acad. Sci. Vol. 902, pp. 230-239.

36. Brooks, A.R., Lelkes, P.I. and Rubanyi, G.M. (2002), 'Gene expression profiling of human aortic endothelial cells exposed to disturbed flow and steady laminar flow', Physiol. Genomics Vol. 9, pp. 24-41.

37. Berliner, J.A. and Heinecke, J.W. (1996), 'The role of oxidized lipoproteins in atherogenesis', Free Radic. Biol. Med. Vol. 20, pp. 707-727. 
38. Virgili, F., Ambra, R., Muratori, F. et al. (2003), 'Effect of oxidized lowdensity lipoprotein on differential gene expression in primary human endothelial cells', Antioxid. Redox Signal Vol. 5, pp. 237-247.

39. Gupta, S. (1999), 'Chronic infection in the aetiology of atherosclerosis Focus on Chlamydia pneumoniae', Atherosclerosis Vol. 143, pp. 1-6.

40. Coombes, B.K. and Mahony, J.B. (2001), 'cDNA array analysis of altered gene expression in human endothelial cells in response to Chlamydia pneumoniae infection', Infect. Immun. Vol. 69, pp. 1420-1427.

41. Higashiyama, S., Abraham, J.A., Miller, J. et al. (1991), 'A heparinbinding growth factor secreted by macrophage-like cells that is related by EGF', Science Vol. 251, pp. 936-939.

42. Ross, R. and Glomset, J.A. (1973), 'Atherosclerosis and the arterial smooth muscle cell', Science Vol. 180, pp. 1332-1339.

43. Eramaa, M., Hurme, M., Stenman, U.H. et al. (1992), 'Activin A/ erythroid differentiation factor is induced during human monocyte activation', J. Exp. Med. Vol. 176, pp. 1449-1452.

44. Ogawa, K., Funaba, M., Mathews, L.S. et al. (2000), 'Activin A stimulates type IV collagenase (matrix metalloproteinase-2) production in mouse peritoneal macrophages', J. Immunol. Vol. 165, pp. 2997-3003.

45. Krüll, M., Klucken, A.C., Wuppermann, F.N. et al. (1999), 'Signal transduction pathways activated in endothelial cells following infection with Chlamydia pneumoniae', J. Immunol. Vol. 162, pp. 4834-4841.

46. Li, H. and Goligorsky, M.S. (2002), 'Endothelial gene responses to homocysteine: Relation to atherosclerosis', Exp. Nephrol. Vol. 10, pp. $164-169$.

47. Weiss, N., Keller, C., Hoffmann, U. et al. (2002), 'Endothelial dysfunction and atherothrombosis in mild hyperhomocysteinemia', Vasc. Med. Vol. 7, pp. 227-239.

48. Zhang, S., Day, I.N. and Ye, S. (2001), 'Microarray analysis of nicotineinduced changes in gene expression in endothelial cells', Physiol. Genomics Vol. 5, pp. 187-192.

49. Takabe, W., Mataki, C., Wada, Y. et al. (2000), 'Gene expression induced by BO-653, probucol and BHQ in human endothelial cells', J. Atheroscler. Thromb. Vol. 7, pp. 223-230.

50. Bandman, O., Coleman, R.T., Loring, J.F. et al. (2002), 'Complexity of inflammatory responses in endothelial cells and vascular smooth muscle cells determined by microarray analysis', Ann. N. Y. Acad. Sci. Vol. 975, pp. $77-90$.

51. Meyer-Kirchrat, J., Debey, S., Glandorff, C. et al. (2004), 'Gene expression profile of the Gs-coupled prostacyclin receptor in human vascular smooth muscle cells', Biochem. Pharmacol. Vol. 67, pp. 757-765.

52. Narumiya, S., Sugimoto, Y. and Ushikubi, F. (1999), 'Prostanoid receptors: Structures, properties, and functions', Physiol. Rev. Vol. 79, pp. $1193-1226$.

53. Zucker, T.P., Bonisch, D., Hasse, A. et al. (1998), 'Tolerance development to antimitogenic actions of prostacyclin but not of prostaglandin E1 in coronary artery smooth muscle cells', Eur. J. Pharmacol. Vol. 345, pp. 213-220.

54. Blindt, R., Krott, N., Hanrath, P. et al. (2002), 'Expression patterns of integrins on quiescent and invasive smooth muscle cells and impact on cell locomotion', J. Mol. Cell. Cardiol. Vol. 34, pp. 1633-1644.

55. Bokemeyer, D., Sorokin, A., Yan, M. et al. (1996), 'Induction of mitogen-activated protein kinase phosphatase 1 by the stress-activated protein kinase signaling pathway but not by extracellular signal-regulated kinase in fibroblasts', J. Biol. Chem. Vol. 271, pp. 639-642.

56. Shields, J.M., Christy, R.J. and Yang, V.W. (1996), 'Identification and characterization of a gene encoding a gut-enriched Kruppel-like factor expressed during growth arrest', J. Biol. Chem. Vol. 271, pp. 20009-20017.

57. Kireeva, M.L., Mo, F.E., Yang, G.P. et al. (1996), 'Cyr61, a product of a growth factor-inducible immediate-early gene, promotes cell proliferation, migration, and adhesion', Mol. Cell. Biol. Vol. 16, pp. $1326-1334$.

58. Filvaroff, E.H., Guillet, S., Zlot, C. et al. (2002), 'Stanniocalcin 1 alters muscle and bone structure and function in transgenic mice', Endocrinology Vol. 143, pp. 3681-3690.

59. Zhu, Y., Farrehi, P.M. and Fay, W.P. (2001), 'Plasminogen activator inhibitor type 1 enhances neointima formation after oxidative vascular injury in atherosclerosis-prone mice', Circulation Vol. 103, pp. $3105-3110$

60. Shin, W.S., Szuba, A. and Rockson, S.G. (2002), 'The role of chemokines in human cardiovascular pathology: Enhanced biological insights', Atherosclerosis Vol. 160, pp. 91-102.

61. Tulis, D.A., Durante, W., Liu, X. et al. (2001), 'Adenovirus-mediated heme oxygenase- 1 gene delivery inhibits injury-induced vascular neointima formation', Circulation Vol. 104, pp. 2710-2715.

62. Wu, K.K. (1995), 'Inducible cyclooxygenase and nitric oxide synthase', Adv. Pharmacol. Vol. 33, pp. 179-207.

63. Blindt, R., Vogt, F., Lamby, D. et al. (2002), 'Characterization of differential gene expression in quiescent and invasive human arterial smooth muscle cells', J. Vasc. Res. Vol. 39, pp. 340-352.

64. Haley, K.J., Lilly, C.M., Yang, J.H. et al. (2000), 'Overexpression of eotaxin and the CCR3 receptor in human atherosclerosis: Using genomic technology to identify a potential novel pathway of vascular inflammation', Circulation Vol. 102, pp. 2185-2189.

65. Graziano, F.M., Cook, E.B. and Stahl, J.L. (1999), 'Cytokines, chemokines, RANTES, and eotaxin', Allergy Asthma Proc. Vol. 20, pp. 141-146.

66. Van Coillie, E., Van Damme, J. and Opdenakker, G. (1999), 'The MCP/eotaxin subfamily of CC chemokines', Cytokine Growth Factor Rev. Vol. 10, pp. 61-86.

67. Ying, S., Robinson, D.S., Meng, Q. et al. (1999), 'C-C chemokines in allergen-induced late-phase cutaneous responses in atopic subjects: Association of eotaxin with early 6-hour eosinophils, and of eotaxin-2 and monocyte chemoattractant protein-4 with the later 24-hour tissue eosinophilia, and relationship to basophils and other C-C chemokines (monocyte chemoattractant protein-3 and RANTES)', J. Immunol. Vol. 163, pp. 3976-3984.

68. Hilker, M., Langin, T., Hake, U. et al. (2003), 'Gene expression profiling of human stenotic aorto-coronary bypass grafts by cDNA array analysis', Eur. J. Cardiothorac. Surg. Vol. 23, pp. 620-625.

69. Pratsos, A.L., Fischman, D.L. and Savage, M.P. (2001), 'Restenosis in saphenous vein grafts', Current Interventional Cardiology Reports Vol. 4, pp. 287-295.

70. Villacorta, L., Graca-Souza, A.V., Ricciarelli, R. et al. (2003), 'Alphatocopherol induces expression of connective tissue growth factor and antagonizes tumor necrosis factor-alpha-mediated down-regulation in human smooth muscle cells', Circ. Res. Vol. 1, pp. 104-110.

71. Schwenke, D.C., Rudel, L.L., Sorci-Thomas, M.G. et al. (2002), 'Alphatocopherol protects against diet induced atherosclerosis in New Zealand white rabbits', J. Lipid Res. Vol. 43, pp. 1927-1938.

72. Ranganna, K., Joshi, T. and Yatsu, F.M. (1995), 'Sodium butyrate inhibits platelet-derived growth factor-induced proliferation of vascular smooth muscle cells', Atheroscler. Thromb. Vasc. Biol. Vol. 15, pp. $2273-2283$.

73. Smith, J.G. and German, J.B. (1995), 'Molecular and genetic effects of dietary derived butyric acid', Food Technol. Vol. 49, pp. 87-90.

74. Wachtershauser, A. and Stein, J. (2000), 'Rationale for the luminal provision of butyrate in intestinal disease', Eur. J. Nutr. Vol. 39, pp. $164-171$.

75. Ranganna, K., Yousefipour, Z., Yatsu, F.M. et al. (2003), 'Gene expression profile of butyrate-inhibited vascular smooth muscle cell proliferation', Mol. Cell. Biochem. Vol. 254, pp. 21-36.

76. Mikita, T., Porter, G., Lawn, R.M. et al. (2001), 'Oxidized low density lipoprotein exposure alters the transcriptional response of macrophages to inflammatory stimulus', J. Biol. Chem. Vol. 276, pp. 45729-45739.

77. Shiffman, D., Mikita, T., Tai, J.T. et al. (2000), 'Large scale gene expression analysis of cholesterol-loaded macrophages', J. Biol. Chem. Vol. 275, pp. 37324-37332.

78. Svensson, P.A., Englund, M.C., Markstrom, E. et al. (2003), 'Copper induces the expression of cholesterogenic genes in human macrophages', Atherosclerosis Vol. 169, pp. 71-76.

79. Salonen, J.T., Salonen, R., Korpela, H. et al. (1991), 'Serum copper and the risk of acute myocardial infarction: A prospective population study in men in eastern Finland', Am. J. Epidemiol. Vol. 134, pp. $268-278$. 
80. Wu, M.M., Chiou, H.Y., Ho, I.C. et al. (2003), 'Gene expression of inflammatory molecules in circulation lymphocytes from arsenic-exposed human subjects', Environ. Health Perspect. Vol. 111, pp. 1429-1438.

81. Ohki, R., Yamamoto, K., Mano, H. et al. (2002), 'Identification of mechanically induced genes in human monocytic cells by DNA microarrays', J. Hypertens. Vol. 20, pp. 685-691.

82. Yue, T.L., Wang, X., Sung, C.P. et al. (1994), 'Interleukin-8. A mitogen and chemoattractant for vascular smooth muscle cells', Circ. Res. Vol. 75, pp. $1-7$.

83. Gerszten, R.E., Garcia-Zepeda, E.A., Lim, Y.C. et al. (1999), 'MCP-1 and IL-8 trigger firm adhesion of monocytes to vascular endothelium under flow conditions', Nature Vol. 398, pp. 718-723.

84. Wu, M.X., Ao, Z., Prasad, K.V. et al. (1998), 'IEX-1L, an apoptosis inhibitor involved in NF-kB-mediated cell survival', Science Vol. 281, pp. $998-1001$

85. Johnstone, R.W., See, R.H., Sells, S.F. et al. (1996), 'A novel repressor, par-4, modulates transcription and growth suppression functions of the Wilms' tumor suppressor WT1', Mol. Cell. Biol. Vol. 16, pp. 6945-6956.

86. Ng, M.K., Quinn, C.M., McCrohon, J.A. et al. (2003), 'Androgens up-regulate atherosclerosis-related genes in macrophages from males but not females: Molecular insights into gender differences in atherosclerosis', J. Am. Coll. Cardiol. Vol. 42, pp. 1306-1313.

87. Wingard, D.L., Suarez, L. and Barrett-Connor, E. (1983), 'The sex differential in mortality from all causes and ischemic heart disease', $\mathrm{Am}$. J. Epidemiol. Vol. 117, pp. 165-172.

88. Jessup, W. and Kritharides, L. (2000), 'Metabolism of oxidized LDL by macrophages', Curr. Opin. Lipidol. Vol. 11, pp. 473-481.

89. Aiello, R.J., Bourassa, P.A., Lindsey, S. et al. (2002), 'Leukotriene B4 receptor antagonism reduces monocytic foam cells in mice', Arterioscler. Thromb. Vasc. Biol. Vol. 22, pp. 443-449.

90. Congestive Heart Failure Data Fact Sheet (2003), www.CHFpatients. com.

91. Tan, F.L., Moravec, C.S., Li, J. et al. (2002), 'The gene expression fingerprint of human heart failure', Proc. Natl. Acad. Sci. USA Vol. 99, pp. 11387-11392.

92. Barrans, J.D., Allen, P.D., Stamatiou, D. et al. (2002), 'Global gene expression profiling of end-stage dilated cardiomyopathy using a human cardiovascular-based cDNA microarray', Am. J. Pathol. Vol. 160, pp. $2035-2043$.

93. Hwang, J.J., Allen, P.D., Tseng, G.C. et al. (2002), 'Microarray gene expression profiles in dilated and hypertrophic cardiomyopathic end-stage heart failure', Physiol. Genomics Vol. 10, pp. 31-44.
94. Steenman, M., Chen, Y.W., Le Cunff, M. et al. (2003), 'Transcriptomal analysis of failing and nonfailing human hearts', Physiol. Genomics Vol. 12, pp. $97-112$.

95. Kang, Y.J., Zhou, Z.X., Wu, H. et al. (2000), 'Metallothionein inhibits myocardial apoptosis in copper-deficient mice: Role of atrial natriuretic peptide', Lab. Invest. Vol. 80, pp. 745-757.

96. Tse, W., Zhu, W., Chen, H.S. and Cohen, A. (1995), 'A novel gene, AF1q, fused to MLL in $\mathrm{t}(1 ; 11)$ (q21;q23), is specifically expressed in leukemic and immature hematopoietic cells', Blood Vol. 85, pp. 650-656.

97. Suetsugu, S., Miki, H. and Takenawa, T. (1998), 'The essential role of profilin in the assembly of actin for microspike formation', $E M B O$ J. Vol. 17, pp. 6516-6526.

98. Yang, J., Moravec, C.S., Sussman, M.A. et al. (2000), 'Decreased SLIM1 expression and increased gelsolin expression in failing human hearts measured by high-density oligonucleotide arrays', Circulation Vol. 102, pp. 3046-3052.

99. Arber, S. and Caroni, P. (1996), 'Specificity of single LIM motifs in targeting and LIM/LIM interactions in situ', Genes Dev. Vol. 10, pp. $289-300$.

100. Arber, S., Hunter, J.J., Ross, Jr, J. et al. (1997), 'MLP-deficient mice exhibit a disruption of cardiac cytoarchitectural organization, dilated cardiomyopathy, and heart failure', Cell Vol. 88, pp. 393-403.

101. Steenbergen, C., Afshari, C.A., Petranka, J.G. et al. (2003), 'Alterations in apoptotic signaling in human idiopathic cardiomyopathic hearts in failure', Am. J. Physiol. Heart Circ. Physiol. Vol. 284, pp. 268-276.

102. Chen, Y., Park, S., Li, Y. et al. (2003), 'Alterations of gene expression in failing myocardium following left ventricular assist device support', Physiol. Genomics Vol. 14, pp. 251-260.

103. Chen, M.M., Ashley, E.A., Deng, D.X. et al. (2003), 'Novel role for the potent endogenous inotrope apelin in human cardiac dysfunction', Circulation Vol. 108, pp. 1432-1439.

104. Blaxall, B.C., Tschannen-Moran, B.M., Milano, C.A. et al. (2003), 'Differential gene expression and genomic patient stratification following left ventricular assist device support', J. Am. Coll. Cardiol. Vol. 41, pp. $1096-1106$.

105. Chen, M.M., Ashley, E.A., Deng, D.X. et al. (2003), 'Novel role for the potent endogenous inotrope apelin in human cardiac dysfunction', Circulation Vol. 108, pp. 1432-1439.

106. Kaynak, B., von Heydebreck, A., Mebus, S. et al. (2003), 'Genome-wide array analysis of normal and malformed human hearts', Circulation Vol. 107, pp. 2467-2474. 